\title{
Pediatric Obstructive Sleep Apnea
}

\author{
Ganpathy Shridhar ${ }^{1}$, Abha Pandey ${ }^{2}$
}

International Journal of Head and Neck Surgery (2019): 10.5005/jp-journals-10001-1370

\section{Case Description}

An 8-year-old girl brought by her parents to the pediatrician for snoring, restless sleep (tossing turning in bed in disarray), choking episodes at times and excessive sweating at night. Patient was under treatment for allergic rhinitis and wheezing. In the last one year, the growth chart is showing faltering, and her school grades had dipped. Of late, there have been complaints from the class teacher for her inattentiveness, and she has stopped participating in extracurricular [sports and social] activities as, she gets extremely fatigued by evening. On examination, BMI $15.35 \mathrm{~kg} / \mathrm{m}^{2}$ and blood pressure $118 / 88 \mathrm{~mm} \mathrm{Hg}$ were recorded.

Dentofacial features: Adenoid facies, long face, narrow chin, mandible in the back position, nasal congestion, high arched palate, maxillary crowding and posterior cross bite. Oral examination showed enlarged tonsils and pale swollen inferior turbinates. PSG showed an $\mathrm{AHI}$ of $10 / \mathrm{hr}$ and lowest $\mathrm{SPO}_{2}-85 \%$.

Sleep-disordered breathing (SDB) in paediatrics is a very prevalent disorder with serious repercussions, representing a spectrum of disorders from primary snoring to frank obstructive sleep apnea (OSA). Pediatic OSA is defined as "disorder of breathing during sleep characterized by prolonged partial upper airway obstruction and/or intermittent complete obstruction (obstructive apnea) that disrupts normal ventilation during sleep and normal sleep patterns," ${ }^{\prime 1}$ accompanied by symptoms or signs, as listed in Table 1.SDB can happen even immediately post birth and anytime in pediatric age group. However, maximum prevalence is seen in 1-8 years, the period of active lymphoid tissue growth. The overall incidence is around $2-4 \% .{ }^{2}$ Prevalence rates based on level I and II studies range from 1.2 to $5.7 \% .^{3}$

\section{Pathophysiology}

Pediatric OSA is a dynamic process. Thus, adult OSA features cannot be extrapolated on them due to the changing physiology and anatomy of a child. OSA in children happens due to primarily intrinsic obstruction in airway or due to increased airway collapsibility leading to a sustained inflammatory state in body (Fig. 1). Long-standing OSA may be associated with hypertension, cardiac dysfunction, and systemic inflammation.

Risk factors established as yet are adenotonsillar hypertrophy, obesity, craniofacial anomalies, neuromuscular disorders and premature birth. Adenotonsillar hypertrophy is currently the most common example of the former. Magnetic resonance imaging (MRI) studies have shown that the size of the adenoids and tonsils in children with OSA is significantly increased compared with healthy controls. ${ }^{4}$ Other anatomical features resulting in upper airway narrowing such as micrognathia, macroglossia, and midface hypoplasia, are usually associated with craniofacial syndromes (e.g., Treacher Collins syndrome, Crouzon syndrome,
'Department of Pediatrics, Janani Children's Hospital, Mumbai, Maharashtra, India

${ }^{2}$ Department of Respiratory Diseases, Lilavati Hospital and Research Center, Mumbai, Maharashtra, India

Corresponding Author: Ganpathy Shridhar, Department of Pediatrics, Janani Children's Hospital, Mumbai, Maharashtra, India, e-mail: sridhar. ganapathy@rediffmail.com

How to cite this article: Shridhar G, Pandey A. Pediatric Obstructive Sleep Apnea. Int J Head Neck Surg 2019;10(2):47-50.

Source of support: Nil

Conflict of interest: None

Table 1: Symptomatology in pediatric OSA

\begin{tabular}{ll}
\hline Diurnal symptoms & Nocturnal symptoms \\
\hline Headaches on awakening & Frequent snoring ( $\geq 3$ nights/week) \\
Attention-deficit/ & Labored breathing during sleep \\
hyperactivity disorder &
\end{tabular}

hyperactivity disorder

Learning problems

Gasps/snorting noises/episodes of apnea

Behavioral problems Sleep enuresis (especially secondary enuresis)

Daytime sleepiness Sleeping in a seated position or with the neck hyperextended

Failure to thrive

Poor scholastic performance

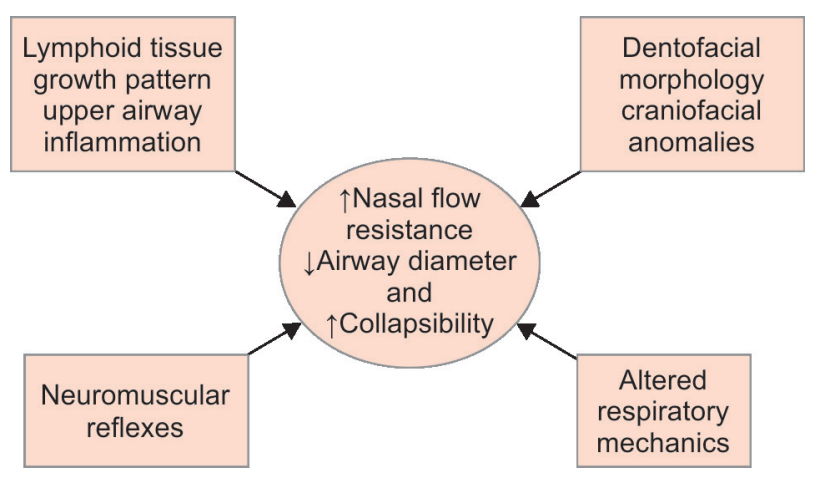

Fig. 1: Genesis of OSA in children

Apert syndrome, Pierre Robin sequence), achondroplasia, trisomy 21 (Down syndrome), Beckwith Wiedemann syndrome, and mucopolysaccharidoses. ${ }^{5}$ Obesity is yet another very important predisposing factor in the pediatric and peripubertal age group. Interestingly, increase in BMI by $1 \mathrm{~kg} / \mathrm{m}^{2}$ increases the risk by $12 \%$. The factors implicated in obesity as a risk factor are pharyngeal fat deposition; decreased thoracic volume and diaphragmatic

(O) The Author(s). 2019 Open Access This article is distributed under the terms of the Creative Commons Attribution 4.0 International License (https://creativecommons. org/licenses/by-nc/4.0/), which permits unrestricted use, distribution, and non-commercial reproduction in any medium, provided you give appropriate credit to the original author(s) and the source, provide a link to the Creative Commons license, and indicate if changes were made. The Creative Commons Public Domain Dedication waiver (http://creativecommons.org/publicdomain/zero/1.0/) applies to the data made available in this article, unless otherwise stated. 
excursion secondary to visceral and abdominal fat deposition and blunted cortical ventilator drive. There is an increased incidence of recurrences of OSA in these patients as well as a high risk to develop postoperative complications. ${ }^{6}$ Increased airway collapsibility as in asthma, allergic rhinitis and neuromuscular disorders also predisposes children to develop OSA and thus should be addressed with appropriate treatment as soon as possible.

\section{Clinical Presentation}

Pediatric OSA has peculiar features which are different from adult OSA (Table 1). In children the complaints are raised by the parents in comparison to the bed partners in adults. In daytime, neurocognitive impairment is much more pronounced with behavioral problems, failure to thrive, learning problems than daytime sleepiness. As the child grows older, daytime somnolence is seen more commonly especially if child is obese. In nighttime, enuresis is a feature restricted to pediatric OSA. Symptomatology in pediatric age group encompasses significant non respiratory complaints too. Normal sleep architecture is maintained thus patients do not experience excessive daytime somnolence. Also, movement arousals secondary to restless sleep is more common in the pediatric age group. Physical examination shows an underweight or overweight child with tonsillar hypertrophy, adenoidal facies, mid facial deficiencies, micrognathia, retrognathia, high-arched palate, dentopalatal aberrations, hypotonia and craniofacial anomalies.

In the syndromic phenotype, Down syndrome needs a special mention as they are prone to develop OSA for a variety of reasonssmall upper airway, midfacial hypoplasia, micrognathia, relative macroglossia, lingual tonsil, decreased immunity and hypotonia; all these contribute to increase collapsibility of upper airway. ${ }^{8}$ Hence, a PSG is a must in all Down's patient before 4 years of age with suggestive symptoms.

\section{DiAgnOSIS}

When the symptomatology and signs point toward OSA, it is prudent to refer the child to a sleep consultant and otolaryngologist. The investigative modalities used in the study of sleep-disordered breathing are many but the gold standard is overnight attended PSG. ${ }^{9}$ Diagnostic criteria need a clinical background to suspect and a PSG finding to confirm OSA (Fig. 2). AHI value is used for diagnosis and staging of pediatric OSA, where in mild OSA is defined as AHI of 1-5 per hour, moderate OSA is AHI of 5-10 per hour and severe OSA is AHI of more than 10 per hour. Lower cut-off in AHI criteria in pediatric age group in comparison to adults is due to

Criteria $A$ and $B$ must be met

A. The presence of 1 or more of the following:

1. Snoring

2. Labored/paradoxical/obstructed breathing during sleep

3. Sleepiness/hyperactivity/behavioral/learning problems

B. PSG demonstrates one or both of the following:

4. One or more obstructive/mixed apneas/hypopneas/ hour of sleep

5. A pattern of obstructive hypoventillation

(Atleast $25 \%$ of TST with $\mathrm{PCO}_{2}>50 \mathrm{~mm} \mathrm{Hg}$ ) in association with

One or more of the following: - Snoring

-Flattening of inspiratory nasal pressure waveforms -Paradoxicalthoracoabdominal motion

Fig. 2: Diagnostic criteria for pediatric OSA ${ }^{9}$ the low functional residual capacity, relatively faster respiratory rate, low muscle mass and easy fatigability of the diaphragm. ${ }^{10}$ Sleep questionnaire, video and audiotaping sleep and nocturnal oximetry are good screening tool in a resource restricted set-up. They are economical and easy to perform, but are only helpful if positive; as they do not record REM sleep, the stage of obstructive events, they may definitely underestimate the presence of SDB. Polysomnography features of pediatric OSA show a slight different trend than that in adults (Table 2). In pediatric age group, predominant obstructive apneas are seen which are REM phase phenomenon. Obese children with OSA behave like adult OSA patients.

In our case, the young girl has typical features of pediatric OSA affecting her scholastic performance and overall development. PSG demonstrates moderate OSA. Thus, this a classical case of pediatric OSA.

\section{Consequences}

Like in adults, OSA in pediatric age group also brings in debilitating consequences with the systemic inflammation all over. Longstanding pediatric OSA is associated with hypertension, cardiac dysfunction, metabolic complications and neurobehavioral compromises as depicted in Figure 3. These consequences are not that commonly seen in children as in adults.

\section{TREATMENT}

Definitive treatment is considered in children with moderate and severe grade of OSA. Mild OSA needs close monitoring with supportive care. Mainstay of treatment as explained above stays surgical intervention where indicated. Weight loss should always be encouraged in all children and even in postoperative phase. PAP therapy and oral appliances are helpful but compliance is a major concern. Compliance to PAP therapy can be improved by educating mothers and introducing the mask in a playful way to child. Family members can contribute by fulfilling the part of play therapist. Drug treatment which includes a trial of intranasal corticosteroids (mometasone or fluticasone or budesonide) and oral leukotriene receptor antagonist montelukast for a period of at least 3 months to reduce mucosal inflammation and adenotonsillar hypertrophy. Nutritional and physical rehabilitation is very important in growing children. Myofunctional therapy a physiotherapy of the orofacial and oropharyngeal muscles as an adjuvant to other therapies is recommended. It has role in lip and tongue posture which favors normal nasomaxillary unit development. ${ }^{11}$ Behavioral therapy in selected patients should be considered. Sleep hygiene is equally important in this age group as well like in adults.

\section{Surgery}

With the understanding and plethora of literature to support, surgical intervention is the first line of treatment in those with evident adenotonsillar hypertrophy as a contrast to adult OSA where surgical intervention comes in picture once PAP therapy fails due to any reason. Adenotonsillectomy is the most commonly performed surgery followed by craniofacial surgeries and tracheostomy. Importantly, postoperative airway and anesthesia complications are a possibility in children with OSA because they already have a blunted ventilatory response to hypoxia and hypercarbia. Adenotonsillectomy is a common surgery done in children but needs to be carefully conducted in children with OSA. A subset of pediatric OSA is more prone to develop postoperative 
Table 2: Childhood versus adult obstructive sleep apnea syndrome

\begin{tabular}{|c|c|c|}
\hline Parameters & Pediatric OSA & Adult OSA \\
\hline Age & Affects all ages, peaks at $1-8$ years & Elderly age group \\
\hline Gender & $\begin{array}{l}\text { Male }=\text { Female (till puberty) } \\
\text { Postpubertal, males have slight preponderance } \\
\text { than females }\end{array}$ & $\begin{array}{l}\text { Male > female (till menopause, then equal preva- } \\
\text { lence noted) }\end{array}$ \\
\hline Risk factors & $\begin{array}{l}\text { - }<1 \text { year: Craniofacial anomalies, syndromes, } \\
\text { neurological disorders } \\
\text { - 1-8 years: Adenotonsillar hypertrophy } \\
\text { - >8 years: Obesity }\end{array}$ & Obesity, craniofacial abnormalities, etc \\
\hline Neurocognitive effects & $\begin{array}{l}\text { ADHD, impaired concentration, performance, low } \\
\text { IQ }\end{array}$ & $\begin{array}{l}\text { Daytime somnolence, impaired vigilance and } \\
\text { memory }\end{array}$ \\
\hline Oral examination & Adenotonsillar hyperhertrphy & Crowded oropharynx \\
\hline $\begin{array}{l}\text { PSG (13) } \\
\text { Apnoea Definition }\end{array}$ & $\begin{array}{l}\text { Cessation of airflow (drop in the Peak signal excur- } \\
\text { sion by } \geq 90 \% \text { ) for at least two respiratory cycles }\end{array}$ & $\begin{array}{l}\text { Cessation of airflow (drop in the Peak signal } \\
\text { excursion by } \geq 90 \% \text { ) } \geq 10 \text { seconds }\end{array}$ \\
\hline Obstruction & $\begin{array}{l}\text { Persistent partial upper airway obstruction (hy- } \\
\text { poventilation) }\end{array}$ & $\begin{array}{l}\text { Frank and cyclic partial or complete upper airway } \\
\text { obstruction }\end{array}$ \\
\hline Transcutaneous $\mathrm{CO} 2$ / End tidal $\mathrm{CO} 2$ & Rise of $\mathrm{PaCO} 2$ & In selected Cases, may be raised \\
\hline Cortical Arousals & $\begin{array}{l}\text { Low frequency of arousals secondary to respirato- } \\
\text { ry events ( } 20 \% \text { of obstructive apnea are followed } \\
\text { by cortical arousal) }\end{array}$ & Apnoeic episodes are followed by arousal \\
\hline Sleep architecture & Normal sleep architecture & Fragmented sleep and decrease in sleep efficiency \\
\hline State of OSA & $\begin{array}{l}\text { Obstructive apnea and hypopneas are a REM } \\
\text { related phenomena }\end{array}$ & Usually occur in both REM and NREM sleep \\
\hline Severity of OSA & $\begin{array}{l}\text { - Mild: } 1-5 \text { events/hour } \\
\text { - Moderate: } 5-10 \text { events/hour } \\
\text { - Severe: }>10 \text { events/hour }\end{array}$ & $\begin{array}{l}\text { - Mild: } 5-15 \text { events/hour } \\
\text { - Moderate: } 15-30 \text { events/hour } \\
\text { - Severe: }>30 \text { events/hour }\end{array}$ \\
\hline Surgical intervention & $\begin{array}{l}\text { If adenotonsillar hypertrophy noted, surgical exci- } \\
\text { sion is mainstay in management }\end{array}$ & $\begin{array}{l}\text { Surgical intervention should be opted for a very } \\
\text { small subset where standard PAP therapy is not } \\
\text { feasible }\end{array}$ \\
\hline
\end{tabular}

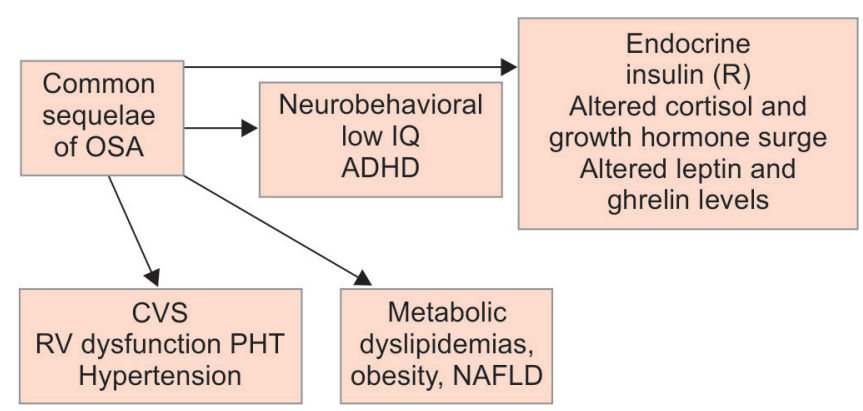

Fig. 3: Consequences in Pediatric OSA

complications like negative pressure pulmonary edema especially in those with severe grade, less than 3 years of age, premature, obese or failure to thrive, down syndrome, craniofacial anomalies, cardiac involvement (right ventricular dysfunction/pulmonary hypertension), chronic lung disease, neuromuscular disorder, sickle cell disease. These children are more prone to the depressive effects of sedatives and opioids used in induction and pain management during and following adenotonsillectomy. ${ }^{12}$ Craniofacial surgeries are restricted to children with syndromic craniofacial anomalies. Tracheostomy is the most definitive intervention in obstructive OSA but rarely performed as it projects the child to a poorer quality of life.

\section{Follow-up PSG}

These corrective interventions can significantly reduce the grade of OSA but may not lead to a definitive cure. Thus, a repeat PSG is recommended postoperatively in these children to establish residual OSA. Generally, PSG is recommended 6 weeks after adenotonsillectomy, after 12 weeks of montelukast/nasal steroid treatment, 12 months after rapid maxillary expansion and after 6 months with orthodontic appliances. Children on CPAP or BPAP should be reevaluated at least every 12 months after initial titration. ${ }^{13,14}$

\section{Pearls of Wisdom}

- Pediatric OSA is a common disorder often underdiagnosed.

- Risk factors should be identified early.

- Symptomatology in pediatric age group is different than adults.

- Diagnosis relies upon suggestive symptoms and confirmatory supervised laboratory PSG like in adults.

- Adenotonsillectomy is the first line of treatment in children who are surgical candidates.

- PAP therapy is equally important but needs innovative ways to improve compliance with children.

- There is a definitive role of orofacial myofunctional therapy in nonobstructive sleep apnea: Focus on myofunctional therapy in obese pediatric OSA.

\section{References}

1. American Thoracic Society. Standards and indications for cardiopulmonary sleep studies in children. Am J Respir Crit Care Med. 1996;153(2):866-878.

2. Kaditis AG. Epidemiologic Aspects of Pediatric OSA around the World. In: Kheirandish-Gozal L, Gozal D, editors. Clinical guide to pediatric sleep medicine. Humana Press; 2012. pp. 279-290. 
3. Li AM, So HK, et al. Epidemiology of obstructive sleep apnoea syndrome in Chinese children: a two-phase community study. Thorax. 2010;65(11):991-999.

4. Slaats MA, Van Hoorenbeeck $K$, et al. Upper airway imaging in pediatric obstructive sleep apnea syndrome. Sleep Med Rev 2015;21:59-71.

5. Eleonora Dehlink. Update on paediatric obstructive sleep apnoea. J Thorac Dis 2016;8(2):224-235.

6. Jodi A Mindell and Judith A Owens. A clinical guide to pediatric sleep. Diagnosis and Management of sleep problems. Wolters Kluwer.2015;3.

7. Clinical Practice Guideline. Diagnosis and Management of Childhood Obstructive Sleep Apnea Syndrome. Pediatrics 2012;130:576-584.

8. $\mathrm{Ng} \mathrm{DK}, \mathrm{Hui} \mathrm{HN}$, et al. Obstructive sleep apnoea in children with Down syndrome. Singapore Med J. 2006 Sep;47(9):774-779.
9. Westchester. American Academy Of Sleep Medicine; Diagnostic and Coding Manual. 2014;3:63.

10. Marcus CL. Sleep-disordered breathing in children. Am J Respir Crit Care Med 2001;164:16-30.

11. Villa, MP \& Evangelisti, Oropharyngeal Exercises for Treatment of Pediatric Obstructive Sleep-Disordered Breathing. M. Curr Sleep Medicine Rep 2019;5: 33.

12. M Patino, S Sadhasivam and M Mahmoud. Obstructive sleep apnoea in children: perioperative considerations. British Journal of Anaesthesia. 2013;111(S1):i83-i95.

13. Kaditis AG, Alonso Alvarez ML, Boudewyns A, et al. Obstructive sleep disordered breathing in 2- to 18-year-old children: diagnosis and management. Eur Respir J 2016;47:69-94.

14. Haya S Alsubie, etal. Obstructive Sleep Apnea: Children are not little adults. Ped Respiratory Reviews 2017;21:72-79. 